\title{
RP-HPLC Method for Estimating Norethindrone in Plasma and Tissues Following Administration of a Controlled Release Nanoparticulate Liquid Formulation
}

\author{
S. S. AL-NIMRY*, B. M. ALTANNI AND R. H. HADDAD \\ Pharmaceutical Technology department, Jordan University of Science and Technology, P. O. Box 3030-Irbid-22110, Jordan
}

Al-Nimry et al.: RP-HPLC method for determination of Norethindrone

\begin{abstract}
The purpose of this investigation was to develop and validate a simple reversed phase-high-performance liquid chromatography method coupled with UV detector estimating norethindrone in plasma and tissues. A Thermo Scientific C18 column $(250 \times 4.6 \mathrm{~mm}$ ID, $5 \mu \mathrm{m}$ pore size) and a mobile phase consisting of deionized water:acetonitrile $(60: 40, \mathrm{v} / \mathrm{v})$ were used. The flow was isocratic at a rate of $1.3 \mathrm{ml} / \mathrm{min}$ and the wavelength of detection was $245 \mathrm{~nm}$. Estradiol was used as internal standard. Validation of linearity, accuracy and precision, limits of detection and quantification, specificity and recovery was carried out according to the International Conference of Harmonization guidelines. The method was used in estimating the bioavailability of a controlled release nanoparticulate liquid formulation, administered to dogs. It was also used estimating adhesion potential of the same formulation to the GIT of mice. The method was simple and only liquid-liquid extraction was used in case of plasma samples. However, sample preparation was more complex in the case of tissue samples. It was linear in the range studied, accurate and precise. It was specific and the excipients used in preparing the formulation did not interfere with the method. The recovery was high and consistent. The bioavailability of the drug was enhanced after the administration of the nanoparticulate liquid formulation as compared to unformulated drug. The formulation adhered to the stomach and intestines for $48 \mathrm{~h}$. After $48 \mathrm{~h}$ the concentration reached undetectable levels. In conclusion, a simple, linear, accurate and precise reversed phase-high-performance liquid chromatography method coupled with UV detection was developed, validated, and used successfully for the determination of norethindrone in plasma and adhesion to GIT tissues. The cost of the analysis was expected to be low sine the extraction procedure was simple and no radiolabeled internal standard was useds.
\end{abstract}

Key words: Norethindrone, RP-HPLC, concentration in plasma, adhesion to tissue, animal models

Norethindrone is a synthetic progesterone (progestin) that belongs to a family of 19-nortestosterone derivatives $^{[1]}$. The structure of norethindrone is shown in fig. $1^{[2]}$. Norethindrone can be used in combination with some oral contraceptive pills or progestin-only pills. Also, it is useful for treatment of certain illnesses and diseases such as premenstrual syndrome, irregular or painful menstruation, abnormal heavy bleeding, to postpone a period or menopausal syndrome (with estrogen). It is also generally used to help in prevention of uterine hemorrhage in complicated non-surgical or pre-surgical gynecologic cases and in treating non responsive cyclical mastalgia ${ }^{[3]}$.

Several methods for the determination of norethindrone alone or with other drugs/metabolites in various dosage forms have been reported. These methods

*Address for correspondence

E-mail: ssnimry@just.edu.jo

July-August 2020 could not be applied as such for the determination of norethindrone in plasma. Norethindrone should be separated from plasma proteins. Also, several methods for the determination of norethindrone in plasma have been developed. A linear high-performance liquid chromatography (HPLC)-UV method in the range 2-20 $\mathrm{ng} / \mathrm{ml}$ was developed. ${ }^{3} \mathrm{H}$-norethindrone radiolabeled internal standard was used and plasma samples were extracted with a mixture of hexanemethylene chloride ${ }^{[4]}$. Another method for the

This is an open access article distributed under the terms of the Creative Commons Attribution-NonCommercial-ShareAlike 3.0 License, which allows others to remix, tweak, and build upon the work non-commercially, as long as the author is credited and the new creations are licensed under the identical terms

Accepted 20 June 2020

Revised 23 May 2020

Received 18 July 2019

Indian J Pharm Sci 2020;82(4):593-600 
www.ijpsonline.com

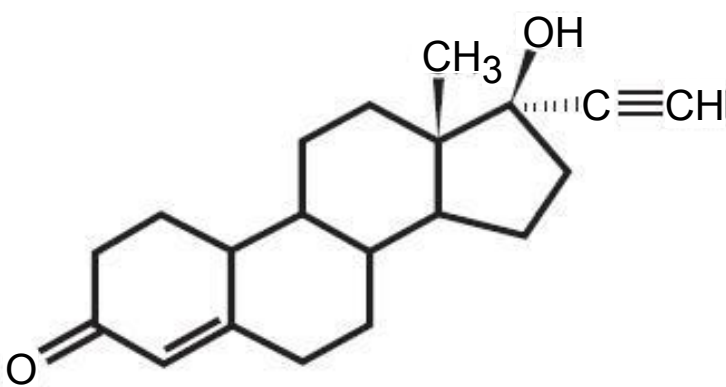

Fig. 1: Structure of norethindrone ${ }^{[2]}$

simultaneous determination of norethisterone and 6 metabolites in human plasma by capillary gas chromatography-mass spectrometry (GC-MS) detection was developed. The compounds were determined in plasma after enzymatic hydrolysis. After addition of norgestrel as an internal standard, the compounds were extracted from plasma at $\mathrm{pH} 5$ using an Extrelut column and elution with dichloromethane. After evaporation, the compounds were converted into bis trimethylsilyl derivatives, which were determined by gas chromatography using a mass-selective detector ${ }^{[5]}$ A HPLC-MS/MS method for the simultaneous determination of norethindrone and ethinyl estradiol in plasma was reported. A derivatizing reagent was used to enhance the sensitivity. The lower limit of quantitation (LLOQ) was 50 and $2.5 \mathrm{pg} / \mathrm{ml}$ for norethindrone and ethinyl estradiol, respectively. Gradient flow of two mobile phases was used to achieve optimal separation of these 2 compounds. Norethindrone${ }^{13} \mathrm{C}_{2}$ and dansylated ethinyl estradiol- $\mathrm{d}_{4}$ were used as internal standards ${ }^{[6]}$. Two semi-automated, relatively high throughput methods using ultra performance liquid chromatography (UPLC) coupled with MS/MS were developed and validated for the simultaneous determination of ethinyl estradiol in combination with either 19-ethindrone or levonorgestrol in human plasma. The concentration ranges were $0.01-2$, and $0.1-20 \mathrm{ng} / \mathrm{ml}$ for ethinyl estradiol and 19-ethindrone or levonorgestrol, respectively. These methods involved liquid-liquid extraction (LLE) and derivatization followed by separation on a small particle size column achieving a run time of $2.7 \mathrm{~min}$. Radiolabeled internal standards were used ${ }^{[7]}$. Another UPLC-MS/ MS method for determination of norethindrone alone in plasma samples over the range of 50-25000 $\mathrm{pg} / \mathrm{ml}$ was developed and validated. Samples were prepared by supported liquid extraction procedure and norethindrone- ${ }^{13} \mathrm{C}_{2}$ was used as the internal standard ${ }^{[8]}$. No specific method was available in literature for determination of norethindrone in GI tissues.
Most of the methods documented above were complicated. In some of these methods sample preparation involved enzymatic hydrolysis followed by column extraction and derivatization. In others it involved LLE, derivatization and separation with small particle size column. Some of these methods involved the use of two mobile phases with gradient flow and some used tandem MS (MS/MS) detection. Additionally, most of these methods used radiolabeled internal standards, which increases the cost of the analysis. Usually these methods are used for the analysis of a large number of samples.

The purpose of this work was to develop and validate a simple, low cost, HPLC method coupled with a UV detector for the determination of norethindrone in plasma and tissues. Sample preparation involved only LLE in case of plasma samples. However, sample preparation from tissue samples became complex. Estradiol used was used as an internal standard. The developed method was used to study the bioavailability of norethindrone after in vivo administration of a previously prepared nanoparticulate liquid formulation (NLF) to $\operatorname{dog} \mathrm{s}^{[9]}$. It was also used to determine the adhesion potential of the formulation to stomach and intestine after in vivo administration to mice.

\section{MATERIALS AND METHODS}

19-Norethindrone $\quad(\geq 98 \quad \%), \quad$ subtilisin, (2-hydroxypropyl)- $\beta$-cyclodextrin (HP- $\beta$-CD) and polyvinyl pyrrolidone (PVP) K30 were supplied by Sigma-Aldrich, USA. $\beta$-estradiol, tert-butyl methyl ether (TBME, $99 \%$ ) and anhydrous dichloromethane were supplied by Across Organics. High molecular weight chitosan (HMWC), 600-800 kDa was supplied by Shanghai Hanshare Industry CO., China. HPLC grade acetone and methanol were supplied by Fisher Scientific, UK. Ammonia solution was supplied by BDH Chemicals, England. Absolute ethanol was supplied by Solvochem, Holland. HPLC grade acetonitrile was supplied by Anhuni Fulltime Specialized Solvents and Reagents Co., China. HPLC grade cyclohexane was supplied by Lab-Scan Analytical Science, Ireland. 0.45 $\mu \mathrm{m}$ Sartolon polyamide cellulose membrane filters were supplied by Sartorius Stedim Biotech, Germany. Tris base was purchased from Bio Basic Inc. (Ontario, Canada). Deionized water prepared in the laboratories of Jordan University of Science and Technology was used throughout the study. Low molecular weight chitosan (LMWC) was prepared by acid hydrolysis of HMWC. 


\section{Liquid chromatographic conditions:}

The analysis of norethindrone was carried out using a Merck Hitachi La Chrom HPLC system, USA. It consisted of a UV/Vis detector (L-7455), an auto sampler (L-7200), an elution pump (L-7150) and a degasser (L7612). The chromatographic separation was done at room temperature on Thermo Scientific C18 (250×4.6 $\mathrm{mm}$ ID, $5 \mu \mathrm{m}$ pore size) column. The mobile phase was composed of deionized water:acetonitrile $(60: 40, \mathrm{v} / \mathrm{v})$. It was filtered through a $0.45 \mu \mathrm{m}$ regenerated cellulose membrane filter prior to use. The flow rate was $1.3 \mathrm{ml} /$ $\min$. The injection volume of sample was $100 \mu \mathrm{l}$. The wavelength of the detection was at $245 \mathrm{~nm}$.

\section{Preparation of calibration standards:}

A stock solution $(100 \mu \mathrm{g} / \mathrm{ml})$ was prepared by dissolving $10 \mathrm{mg}$ of norethindrone in $100 \mathrm{ml}$ of ethanol. Seven standard solutions were prepared by appropriate dilution of the stock solution with plasma, which were, 0.04, 0.08, 0.16, 0.31, 0.63, 1.25 and 2.50 $\mu \mathrm{g} / \mathrm{ml}$. Estradiol was used as internal standard. A stock solution $(1000 \mu \mathrm{g} / \mathrm{ml})$ was prepared by dissolving 10 $\mathrm{mg}$ of estradiol in $10 \mathrm{ml}$ ethanol.

\section{Liquid-liquid extraction of plasma samples:}

Five hundred microlitres of plasma was spiked with $20 \mu \mathrm{l}$ of estradiol (internal standard $1000 \mu \mathrm{g} / \mathrm{ml}$ ) and vortexed. $3 \mathrm{ml}$ of dichloromethane:hexane (40:60, $\mathrm{v} / \mathrm{v}$ ) was added to the plasma sample and vortexed. The sample was centrifuged for $4 \mathrm{~min}$ at $4000 \mathrm{rpm}$. Appropriate amount of the organic phase was transferred to a 5-ml test tube, evaporated in a concentrating dryer at $35^{\circ}$ with a cold trap for about $1 \mathrm{~h}$. The residue was immediately reconstituted with $300 \mu 1$ of mobile phase and analyzed using the developed and validated RPHPLC method. The RP-HPLC method of analysis for norethindrone was validated in terms of linearity, accuracy and precision, Limit of detection (LOD) and limit of quantitation (LOQ), specificity and recovery according to the ICH Guidelines ${ }^{[10]}$.

Linearity was determined by injecting the 7 prepared standard solutions and plotting peak area ratio of norethindrone to estradiol versus norethindrone concentrations to construct a calibration curve. Six calibration curves were prepared on different days. The correlation coefficient (R), $y$-intercept, and the slope of the regression line were computed. The results were analyzed using one-way analysis of variance (ANOVA) at a significance level of $\alpha=0.05$ (95\% of confidence interval) using JMP statistical analysis software.

Accuracy and precision of the method were evaluated on 3 consecutive days by preparing QC samples of norethindrone at 3 concentration levels, 0.05 (low), 0.5 (medium) and $2 \mu \mathrm{g} / \mathrm{ml}$ (high) from the stock solution. The results were analyzed by one-way ANOVA test at a significance level of $\alpha=0.05$ (95\% of confidence interval) using JMP statistical analysis software.

LOD and LOQ were calculated using Eqns., $\mathrm{LOD}=(3.3 \times \sigma) / \mathrm{s}$ and LOQ $=(10 \times \sigma) / \mathrm{s}$, where, $\sigma$ is the standard deviation of the response and $\mathrm{s}$ is the slope of the calibration curve. Specificity was evaluated to ensure that the peaks of the excipients used in the preparation of the NLF (LMWC, HP- $\beta-C D$ and PVP K30) were resolved from the peak of the drug. Samples were spiked with the appropriate levels of these excipients and injected to demonstrate that the assay of the drug was not affected by their presence. Recoveries of norethindrone and estradiol were evaluated by comparing peak areas in dog plasma before and after extraction. The recovery of norethindrone was determined at 3 concentration levels $(0.05,0.5$ and 2 $\mu \mathrm{g} / \mathrm{ml})$ and the recovery of estradiol was determined at $20 \mu \mathrm{l}(1000 \mu \mathrm{g} / \mathrm{ml})$. Two sets of samples were prepared. In the first set (before extraction) blank plasma samples were spiked with the drug solution $(0.05,0.5$ and 2 $\mu \mathrm{g} / \mathrm{ml})$ and $20 \mu \mathrm{g} / \mathrm{ml}$ of estradiol $(1000 \mu \mathrm{g} / \mathrm{ml})$ then extracted as mentioned above. In the second set (after extraction) the blank samples were first extracted and the residue was spiked with norethindrone and the internal standard, reconstituted with the mobile phase, and injected. NLF was prepared and the details of the preparation and optimization of the NLF were published previously ${ }^{[9]}$.

\section{Bioavailability study in the dog:}

All experiments were carried out in accordance with Institutional Guidelines Animal Use for Jordan University of Science and Technology. Oral bioavailability of the NLF was evaluated using a single dose cross over study design. Six dogs (8 mo old) weighing about $30 \mathrm{~kg}$ and from Kinnani family were used. The dogs were randomly divided into 2 groups, 3 dogs were orally administered $10 \mathrm{ml}$ of the test formulation (NLF) and the other 3 dogs were orally administered $10 \mathrm{ml}$ of the reference formula (norethindrone dissolved in ethanol:water solution (40:50, v/v) using a syringe. The norethindrone dose 
for both groups was $0.1455 \mathrm{mg} / \mathrm{ml}$. About $2 \mathrm{ml}$ blood samples were collected from the suborbital vein with a heparinized syringe from both groups at predetermined time intervals $(0,0.5,1,2,4,6,8,12,24,48,72$ and $96 \mathrm{~h}$ ). Blood samples were immediately centrifuged at $5000 \mathrm{rpm}$ for $5 \mathrm{~min}$. The plasma obtained was stored in Eppendorf tubes at $-20^{\circ}$ until analysis. The procedure was repeated after $2 \mathrm{w}$ where the first group received the reference drug formula and the second group received the test formulation in a cross-over design. The analysis was carried out using the developed and validated RPHPLC method. Plasma concentration-time profiles for the NLF and norethindrone were constructed

\section{Adhesion to GIT in mice:}

The adhesion potential of the NLF was evaluated in 4 mo old mice (Mus musculus) weighing about 28 g. Twenty mice were randomly divided into 5 groups of 4 mice each. All mice were orally administered about $1 \mathrm{ml}$ of the test formulation containing 0.16 $\mathrm{mg}$ of norethindrone using a feeding tube. The mice were subjected to light ether anesthesia. The stomach and intestine were collected from each mouse at predetermined time intervals and stored at $-20^{\circ}$ until analysis. The time intervals after administration were, group $12 \mathrm{~h}$, group $224 \mathrm{~h}$, group $348 \mathrm{~h}$, group $472 \mathrm{~h}$ and group 5 after $96 \mathrm{~h}$ of administration. Norethindrone that had attached to the tissue of the stomach or intestines was extracted according to method developed by Kaklamanos et al. ${ }^{[11]}$. Tissue sample were subjected to enzymatic hydrolysis, extracted with tert-butyl methyl ether, defatted and subjected to solid phase extraction (SPE). The resultant residue was reconstituted with 300 $\mu 1$ of methanol and analyzed using the validated HPLCUV method.

\section{RESULTS AND DISCUSSION}

Several researchers used radiolabeled internal standards for analyzing contraceptive hormones, but this increased the cost of the analysis. The radiolabeled compounds could be replaced by analog hormones for contraception ${ }^{[5,12]}$. $\beta$-estradiol was selected as the internal standard due to the structural similarity to norethindrone. The injection volume, for the size of the column used, $4.6 \mathrm{ID} \times 250 \mathrm{~mm}$, usually ranges between 0-40 microliter. However, a larger volume $(100 \mu \mathrm{l})$ was used in this study. This increased the sensitivity of the method without adversely affecting the peak shape, symmetry, and resolution. The peaks of norethindrone and the internal standard (estradiol) were sharp, symmetrical, and well resolved even at the highest concentration. The peak of estradiol appeared at a retention time of $7.23 \pm 0.2 \mathrm{~min}$ and the peak of norethindrone at $9.04 \pm 0.2 \mathrm{~min}$ (fig. 2).

Validation of an analytical procedure is a proof that it is suitable for its intended use. The method of analysis was validated according to the ICH guidelines ${ }^{[10]}$ in term of linearity, accuracy, precision, specificity, sensitivity, LOD and LOQ. Linearity of an analytical method describes its ability to give results for conducted test that are directly proportional to the quantity of analyte in the sample ${ }^{[10]}$. It is generally evaluated by plotting the area ratio (area under the peak of the drug to that under the peak of the internal standard) against the concentration of the drug. From the plot, correlation coefficient, y-intercept, and slope can be obtained. Linearity in this investigation was evaluated by injecting 7 standard solutions $(0.04,0.08,0.16,0.31,0.63,1.25$ and $2.50 \mu \mathrm{g} / \mathrm{ml}$ ) into the system. Six calibration curves were injected on different days and the data were represented in Table 1. The coefficient of correlation (R) value was greater than 0.999 for all the 6 calibration curves, which is generally considered as evidence of acceptable fit of the data to the regression line $\mathrm{e}^{[13]}$. The linear fit for the obtained data is shown in fig. 3. The results of the ANOVA test for the calibration curves are shown in Table 2. The p-value $>0.05$ indicated that the null hypothesis is not rejected and that there was no significant difference between the calibration curves run on different days.

Accuracy of an analytical method measures the closeness of agreement between the resulted practical value obtained from the test and the expected real theoretical value of the analyte in the sample. The ICH guidelines recommend for accuracy assessment using a minimum of 9 determinations over a minimum of

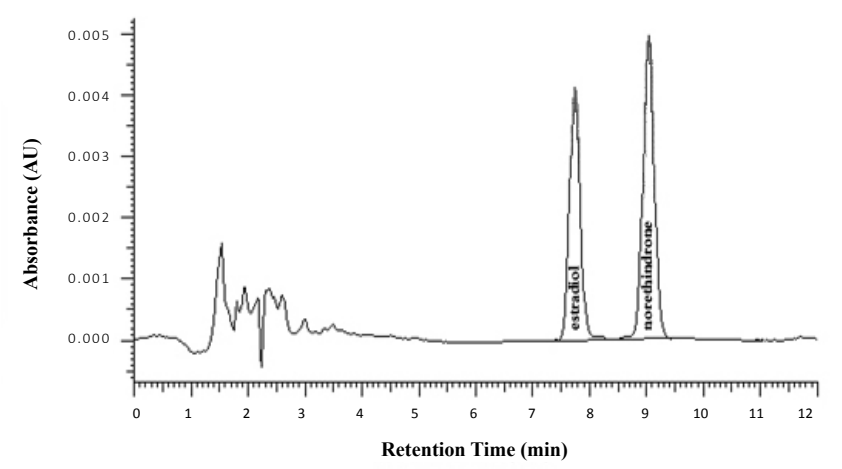

Fig. 2: Chromatogram of spiked plasma sample. Chromatogram of a plasma sample spiked with $2 \mu \mathrm{g} / \mathrm{ml}$ estradiol (internal standard) and $0.63 \mu \mathrm{g} / \mathrm{ml}$ norethindrone. 
3 concentration levels, covering the specified range (i.e., 3 concentrations and 3 replicates of each concentration) ${ }^{[10]}$. It is calculated as percent recovery ${ }^{[14]}$ using the Eqn., $\%$ accuracy $=100-(($ theoretical value-experimental value/theoretical value $) \times 100$ )

The precision of an analytical procedure is the degree of agreement among individual test results when the procedure is performed repeatedly to multiple samplings of a homogeneous sample. The precision of an analytical procedure is usually analyzed by examining the standard deviation or relative standard deviation (coefficient of variation) of a series of measurement. According to the $\mathrm{ICH}$, precision should be performed at three different levels; repeatability, intermediate precision (inter-day precision) and reproducibility (between laboratories precision) ${ }^{[12]}$. Repeatability is the intra-day variation in assay obtained at different concentration levels using the same analyst with the same equipment expressed in terms of RSD calculated for each day. Intermediate precision is the inter-day variations expresses within-laboratory variation, as on different days, or with different analysts or equipment within the same laboratory ${ }^{[15]}$. Reproducibility is the precision between laboratories (collaborative or inter-laboratory studies) ${ }^{[16]}$. Precision is expressed statistically as standard deviation (SD) or coefficient of variation $(\mathrm{CV})$ or the relative standard deviation (RSD) which is calculated using Eqn. 4, \% RSD $=$ standard deviation/average $\times 100$.

Typically, for assay methods, RSD between the two sets of data must be $\leq 2.0 \%{ }^{[13,17]}$. Acceptance criteria similar to those applied to intermediate precision also apply to reproducibility ${ }^{[16]}$. The intra- and inter-day accuracy and precision were determined using six QC samples at three concentration levels (QC low $(0.05 \mu \mathrm{g} / \mathrm{ml})$, QC medium $(0.5 \mu \mathrm{g} / \mathrm{ml})$ and QC high $(2 \mu \mathrm{g} / \mathrm{ml}))$. These QC samples were prepared and injected on three consecutive days. Additionally, 6 LLOQ samples were injected on the first day of the validation. The results are shown in Table 3 . The

TABLE 1: LINEARITY DATA AND PARAMETERS OF NORETHINDRONE CALIBRATION ON DIFFERENT DAYS

\begin{tabular}{|c|c|c|c|c|c|c|c|c|c|c|}
\hline & \multicolumn{7}{|c|}{ Concentration $(\mu \mathrm{g} / \mathrm{ml})$} & \multirow{3}{*}{ Slope } & \multirow{3}{*}{ Intercept } & \multirow{3}{*}{$\mathbf{R}^{2}$} \\
\hline & 0.04 & 0.08 & 0.16 & 0.31 & 0.63 & 1.25 & 2.50 & & & \\
\hline & \multicolumn{7}{|c|}{ Area Under Peak (AU) } & & & \\
\hline 1 & 0.0780 & 0.1488 & 0.3665 & 0.6811 & 1.2521 & 2.5724 & 4.8677 & 1.949 & 0.042 & 0.9991 \\
\hline 2 & 0.0795 & 0.1511 & 0.3887 & 0.6799 & 1.2611 & 2.5833 & 4.9881 & 1.992 & 0.035 & 0.9995 \\
\hline 3 & 0.0882 & 0.1661 & 0.3555 & 0.6541 & 1.2522 & 2.5711 & 5.0254 & 2.007 & 0.022 & 0.9998 \\
\hline 4 & 0.0755 & 0.1477 & 0.3551 & 0.6832 & 1.2384 & 2.4611 & 4.779 & 1.905 & 0.041 & 0.9995 \\
\hline 5 & 0.0722 & 0.1495 & 0.3761 & 0.6689 & 1.2433 & 2.5412 & 4.8412 & 1.936 & 0.040 & 0.9993 \\
\hline 6 & 0.0912 & 0.1578 & 0.3489 & 0.6381 & 1.2577 & 2.5551 & 4.8512 & 1.943 & 0.037 & 0.9994 \\
\hline Mean & 0.0808 & 0.1535 & 0.3651 & 0.6676 & 1.2508 & 2.5474 & 4.8921 & 1.9553 & 0.0362 & 0.9994 \\
\hline SD & 0.0074 & 0.0071 & 0.0151 & 0.0181 & 0.0086 & 0.0448 & 0.0945 & 0.0377 & 0.0074 & 0.0002 \\
\hline RSD & 9.1738 & 4.6500 & 4.1254 & 2.7056 & 0.6853 & 1.7574 & 1.9313 & 1.9290 & 20.4994 & 0.0234 \\
\hline
\end{tabular}

TABLE 2: RESULTS OF ANOVA FOR THE LINEARITY DATA OF NORETHINDRONE

\begin{tabular}{lccccc}
\hline Source of variation & DF & SS & MS & F Ratio & Probability $>$ F \\
\hline Between groups & 1 Model & 0.0160 & 0.003 & 0.001 & 1.0000 \\
Within group & 40 Error & 110.6318 & 3.0735 & & \\
Total & 41 C. Total & 110.6474 & & & \\
\hline
\end{tabular}

DF-degrees of freedom; SS-sum of squares; MS-mean square; ${ }^{*} p<0.05$

TABLE 3: INTRA-DAY ACCURACY AND PRECISION AT LOQ AND INTRA- AND INTER-DAY ACCURACY AND PRECISION AT DIFFERENT CONCENTRATION LEVELS

\begin{tabular}{lccccccc}
\hline QCs & $\begin{array}{c}\text { Concentration } \\
(\mu \mathrm{g} / \mathrm{ml})\end{array}$ & \multicolumn{3}{c}{ Intra-day assay } & \multicolumn{3}{c}{ Inter-day assay } \\
\cline { 2 - 8 } & 0.04 & 0.04 & 100.10 & 0.14 & & & Accuracy \\
LLOQ & 0.05 & 0.05 & 100.00 & 1.76 & 0.05 & 100 & 0.38 \\
Low QC & 0.50 & 0.50 & 100.00 & 1.85 & 0.50 & 100 & 0.2 \\
Mid QC & 2.00 & 2.02 & 100.01 & 1.62 & 2.02 & 100.02 & 0.36 \\
High QC & 2.02 &
\end{tabular}

Intra-day accuracy and precision at the lower limit of quantitation (LOQ) and intra- and inter-day accuracy and precision at different concentration levels, $\mathrm{N}=6$ 
intra-day accuracy and precision at the LLOQ were $100.10 \%$ and 0.14 , respectively. The intra-day accuracy and precision at the low QC, mid QC, and high QC ranged between 100.00-100.01\% and 1.621.85 , respectively. The inter-day accuracy and precision at the low QC, mid QC, and high QC ranged between $100.00-100.02 \%$ and $0.20-0.38$, respectively. This indicated that the accuracy and precision at the LLOQ and at the three concentration levels (intra-and interday) met the acceptance criteria ${ }^{[13,18-20]}$. The results of the ANOVA test for the QC samples are presented in Table 4. The p-value $>0.05$ (0.7411 for QC high and 0.7281 for QC mid) indicated that the null hypothesis is not rejected and that there was no significant difference between the QC samples run on the same day or on different days.

LOD of an analytical procedure is the lowest amount of analyte in a sample which can be detected but not necessarily quantitated as an exact value. The LOQ is the lowest amount of analyte in a sample which can be quantitatively determined with suitable precision and accuracy ${ }^{[10]}$. For norethindrone method of analysis, LOD and LOQ were estimated from the standard deviation of the blank. The calculated LOD and LOQ were 0.0154 and 0.0264 , respectively. Experimental value of the LLOQ was $0.04 \mu \mathrm{g} / \mathrm{ml}$ which is the lowest

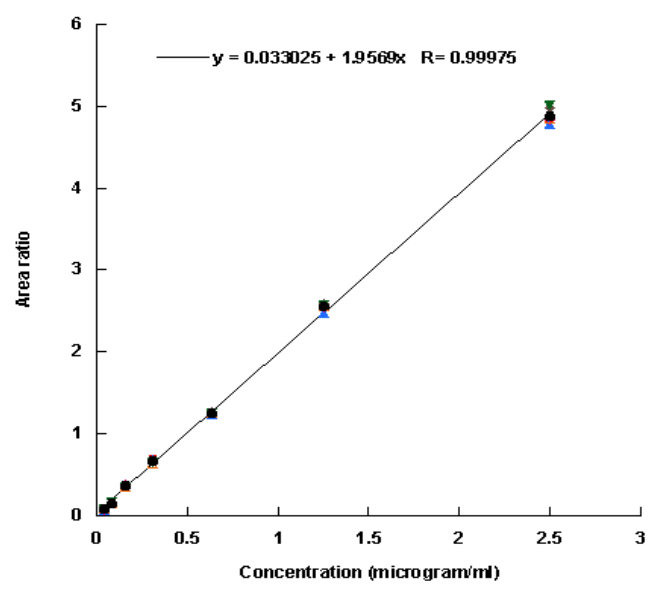

Fig. 3: Linear fit for 6 calibration curves of norethindrone on different days

TABLE 4: INTER-AND INTRA-DAY ACCURACY AND PRECISION AT DIFFERENT CONCENTRATION LEVELS

\begin{tabular}{|c|c|c|c|c|c|c|}
\hline & Source of variation & DF & SS & MS & F Ratio & Probability > F \\
\hline \multirow{3}{*}{ QC Mid } & Between groups & 2 Day & 0.00002 & 0.00001 & 0.064 & 0.9382 \\
\hline & Within group & 15 Error & 0.0013 & 0.00009 & & \\
\hline & Total & $17 \mathrm{C}$ & 0.0013 & & & \\
\hline \multirow[t]{3}{*}{ QC High } & Between groups & 2 Day & 0.0009 & 0.0005 & 0.400 & 0.6775 \\
\hline & Within group & 15 Error & 0.0175 & 0.0012 & & \\
\hline & Total & $17 \mathrm{C}$ & 0.0185 & & & \\
\hline
\end{tabular}

DF-degrees of freedom; SS-sum of squares; MS-mean square; * $p<0.05$ 
(a)

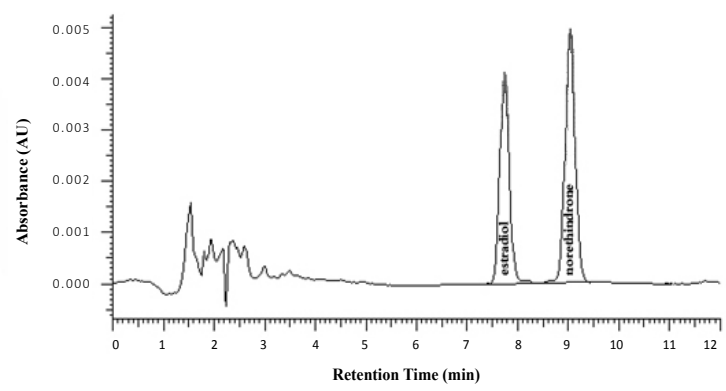

(b)

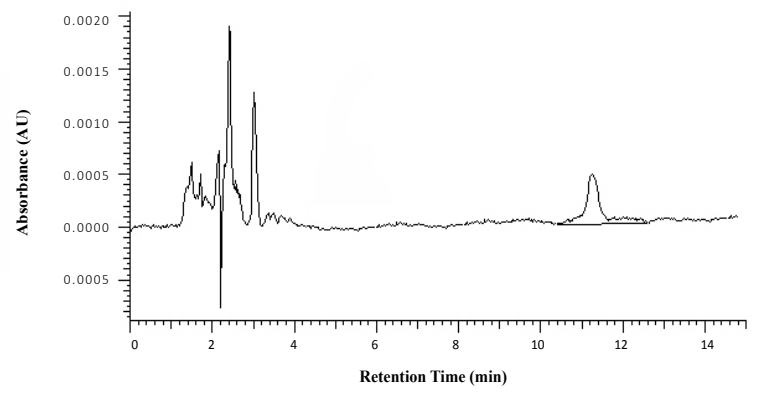

(c)

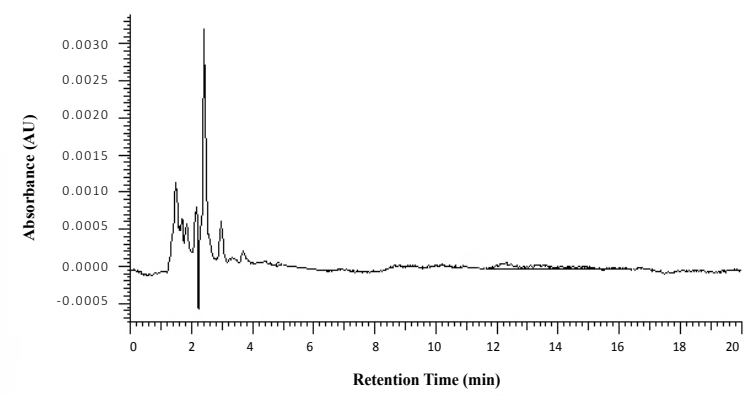

(d)

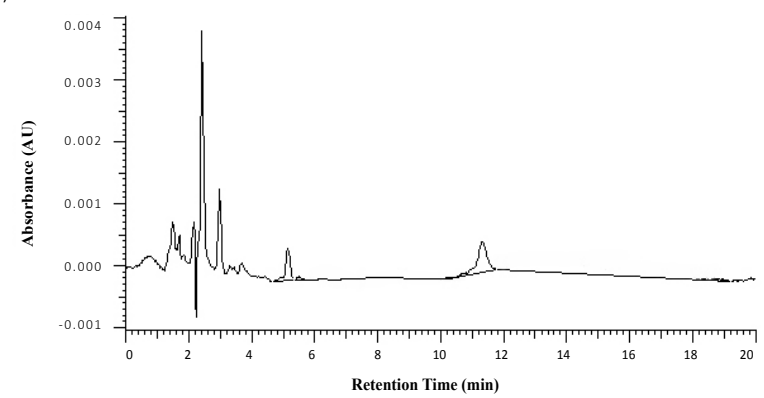

Fig. 4: Chromatograms indicating specificity of the HPLC method

(a) Estradiol internal standard $(2 \mu \mathrm{g} / \mathrm{ml})$ and norethindrone $(0.63 \mu \mathrm{g} / \mathrm{ml}$ ) (b) Chitosan (c) HP-ß-CD and (d) PVP K30 in plasma in these organs decreased with time and almost reached undetectable level after $48 \mathrm{~h}$. However, analysis of dog plasma indicated the presence of norethindrone for $96 \mathrm{~h}$.

In conclusion, a new RP-HPLC method coupled with UV detection was developed and validated for the determination of norethindrone in plasma and tissue. The method was simple, the sample preparation from plasma involved only LLE, the elution was isocratic and a single detector was used. It was linear in the range studied, and the statistical analysis proved it was accurate and precise. The excipients used in the formulation did not interfere in the analysis of norethindrone. The recoveries of norethindrone and the internal standard from plasma were high and consistent. The cost was expected to be low as compared to the other reported methods specially those using complex sample preparation procedures and radiolabeled internal standards. The method was successfully applied to a bioavailability of norethindrone after administration of a NLF and the adhesion potential to GI tissue in animal model.

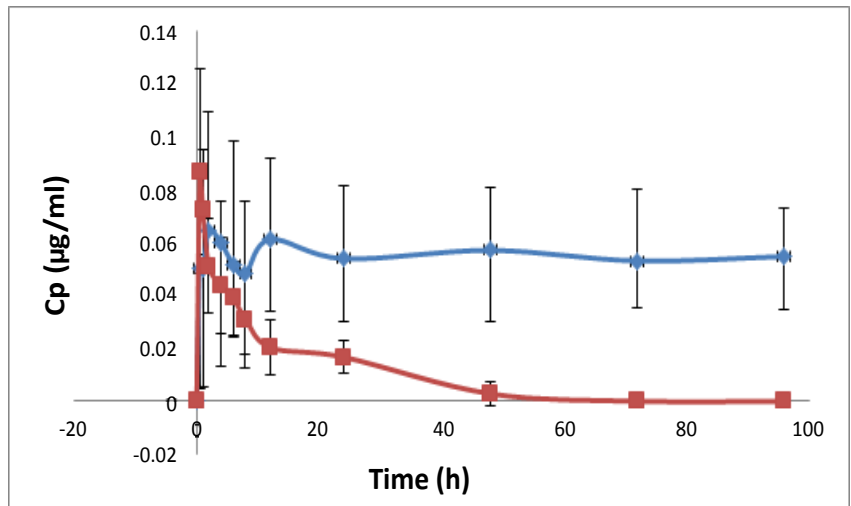

Fig. 5: Plasma concentration time profile of norethindrone given orally to dogs

Average plasma concentration time profile of norethindrone after administration of $10 \mathrm{ml}(0.1455 \mathrm{mg} / \mathrm{ml})$ of the pure drug or the test formulation orally to dogs $(n=6),(-\downarrow-)$ nanoparticle formulation of norethindrone; $(-\square)$ raw norethindrone

TABLE 5: EXTRACTION RECOVERY OF NORETHINDRONE AT DIFFERENT CONCENTRATION LEVELS AND ESTRADIOL

\begin{tabular}{|c|c|c|c|c|c|}
\hline \multirow[b]{2}{*}{ Substance } & \multirow[b]{2}{*}{$\begin{array}{l}\text { Concentration } \\
(\mu \mathrm{g} / \mathrm{ml})\end{array}$} & \multicolumn{2}{|c|}{ Peak area } & \multirow[b]{2}{*}{ \% Recovery } & \multirow[b]{2}{*}{$\begin{array}{l}\text { Coefficient of } \\
\text { Variation }\end{array}$} \\
\hline & & $\begin{array}{c}\text { Samples spiked } \\
\text { before extraction) }\end{array}$ & $\begin{array}{c}\text { Samples spiked after } \\
\text { extraction }\end{array}$ & & \\
\hline \multirow[t]{3}{*}{ Norethindrone } & 0.05 & 8911 & 7846 & 113.57 & 5.12 \\
\hline & 0.50 & 57522 & 59492 & 96.69 & 7.42 \\
\hline & 2.00 & 201626 & 209423 & 96.28 & 9.11 \\
\hline Estradiol & 2.00 & 87773 & 100699 & 87.16 & 3.22 \\
\hline
\end{tabular}

Estradiol at $1000 \mu \mathrm{g} / \mathrm{ml}$ from plasma 
TABLE 6: ADHESION TO GASTROINTESTINAL TRACT AFTER TEST FORMULATION

\begin{tabular}{lcc}
\hline $\begin{array}{l}\text { Time }(\mathrm{h}) \text { following } \\
\text { administration }\end{array}$ & $\begin{array}{c}\text { Weight of tissue } \\
(\mathrm{g})\end{array}$ & $\begin{array}{c}\text { Concentration of } \\
\text { drug in tissue }(\mu \mathrm{g} / \mathrm{g})\end{array}$ \\
\hline 2 & $4.01 \pm 0.37$ & $7.74 \pm 0.75$ \\
24 & $3.41 \pm 0.56$ & $1.37 \pm 0.17$ \\
48 & $3.38 \pm 0.41$ & $0.08 \pm 0.01$ \\
72 & $2.93 \pm 0.85$ & $<$ LLOQ \\
96 & $3.16 \pm 0.32$ & $<$ LLOQ \\
\hline
\end{tabular}

Adhesion to gastrointestinal tract after administration of $1 \mathrm{ml}$ of the test formulation containing $0.16 \mathrm{mg}$ of norethindrone, $\mathrm{N}=4 \mathrm{~N}=4$

\section{Acknowledgements:}

The authors thank the Jordan University of Science and Technology for financial support (347/2015).

\section{Conflict of Interest:}

The authors declare that they have no conflict of interest.

\section{REFERENCES}

1. Schindler AE, Campagnoli C, Druckmann R, Huber J, Pasqualini JR, Schweppe KW, Thijssen JH. Classification and pharmacology of progestins. Maturitas 2003;46:S7-S16.

2. Norethindrone Tablets. [cited 25 March 2017] Available from: https://www.drugs.com/pro/norethindrone-tablets.html/

3. Santos M, Hendry D, Sangi-Haghpeykar H, Dietrich JE. Retrospective review of norethindrone use in adolescents. J Pediatr Adolesc Gynecol 2014;27:41-44.

4. Loo JC, Brien R. Analysis of norethindrone in plasma by high-performance liquid chromatography. J Liq Chromatogr 1981;4:871-7.

5. Pommier F, Sioufi A, Godbillon J. Simultaneous determination of norethisterone and six metabolites in human plasma by capillary gas chromatography with mass-selective detection. J Chromatogr B 1995;674;155-165.

6. Li W, Li YH, Li AC, Zhou S, Naidong W. Simultaneous determination of norethindrone and ethinyl estradiol in human plasma by high performance liquid chromatography with tandem mass spectrometry--experiences on developing a highly selective method using derivatization reagent for enhancing sensitivity. J Chromatogr B Analyt Technol 2005;825:223-32.

7. Licea-Perez H, Wang S, Bowen CL, Yang E. A semi-automated 96-well plate method for the simultaneous determination of oral contraceptives concentrations in human plasma using ultra performance liquid chromatography coupled with tandem mass spectrometry. J Chromatogr B 2007;852:69-76.
8. Gong Z, Chandler K, Webster S, Kerley R, Buist S, McCortTipton M. Simple and rapid determination of norethindrone in human plasma by supported liquid extraction and ultraperformance liquid chromatography with tandem mass spectrometry. Talanta 2012;91:77-82.

9. Altaani BM, Al-Nimry SS,1,3 Haddad RH, Abu-Dahab R. Preparation and characterization of an oral norethindrone sustained release/controlled release nanoparticles formulation based on chitosan. AAPS PharmSciTech 2019;20:54-67.

10. ICH, Q2R1, Harmonized Tripartite Guidline, Validation of analytical procedures: text and methodology. Proceedings of the International Conference on Harmonization, Geneva, March, 1994.

11. Kaklamanos G, Theodoridis G, Papadoyannis IN, Dabalis T. Determination of anabolic steroids in muscle tissue by liquid chromatography-tandem mass spectrometry. J Agric Food Chem 2007;55(21):8325-30.

12. Harahap Y, Devina D, Harmita H. Determination of Ethinyl Estradiol and Levonorgestrel in Human Plasma with Prednisone as Internal Standard Using Ultra-performance Liquid Chromatography-Tandem Mass Spectrometry. J Pharm Bioallied Sci. 2019;11:254-261.

13. Suresh R, Anarthanan SVJ, Manavalan R, Valliappan $\mathrm{K}$. Aspects of validation in HPLC method development for pharmaceutical analysis - Comparison of validation requirements by FDA, USA and $\mathrm{ICH}$. Int J Pharm Sci Res 2010;12:123-33.

14. Validation of Compendial Procedures. USP30-NF25, United States Pharmacopoeia/National Formulary. 30th ed. Rockville, MD: Pharmacopeial Convention; 2008.

15. United States Pharmacopoeia/National Formulary. 30th ed. Rockville, MD: Pharmacopeial Convention; 2008.

16. Rao R, Talluri MVK, Raju AN, Shinde DD, Ramanjaneyulu GS. Development of a validated RP-LC/ESI-MS-MS method for separation, identification and determination of related substances of tamsulosin in bulk drugs and formulations. J Pharm Biomed 2008;46:94-103.

17. Reddy LS, Reddy SLNP, Reddy GS. Development and validation of a stability indicating liquid chromatographic method for simultaneous estimation of Dutasteride and Tamsulosin in combined dosage form. Orient $\mathrm{J}$ Chem 2014;29:1665-73.

18. Tiwari G, Tiwari R. Bioanalytical method validation: an updated review. Pharm Methods 2010; 1(1):25-38.

19. Food, Drug Administration Centre for Drug Evaluation and Research (FDA). Guidance for Industry-Bioanalytical Method Validation, Center for Drug Evaluation and Research, US Department for Health and Human Services, Silver Spring, MD, 2013 (May 2001).

20. Lindholm J. Development and validation of HPLC methods for analytical and preparative purposes. [Dissertation] Uppsala: Acta Universitatis Upsaliensis; 2004. p. 87. 